\title{
Article \\ The Study of the New Classes of m-Fold Symmetric bi-Univalent Functions
}

\author{
Daniel Breaz ${ }^{1}$ and Luminiţa-Ioana Cotîrlă ${ }^{2, *(D)}$ \\ 1 Department of Mathematics, University of Alba Iulia, 510009 Alba Iulia, Romania; dbreaz@uab.ro \\ 2 Department of Mathematics, Technical University of Cluj-Napoca, 400114 Cluj-Napoca, Romania \\ * Correspondence: luminita.cotirla@math.utcluj.ro
}

check for

updates

Citation: Breaz, D.; Cotîrlă, L.-I. The Study of the New Classes of m-Fold Symmetric bi-Univalent Functions. Mathematics 2022, 10, 75. https:// doi.org/10.3390/math10010075

Academic Editor: Juan B.

Seoane-Sepúlveda

Received: 7 December 2021

Accepted: 24 December 2021

Published: 27 December 2021

Publisher's Note: MDPI stays neutral with regard to jurisdictional claims in published maps and institutional affiliations.

Copyright: (c) 2021 by the authors Licensee MDPI, Basel, Switzerland. This article is an open access article distributed under the terms and conditions of the Creative Commons Attribution (CC BY) license (https:// creativecommons.org/licenses/by/ $4.0 /)$.
Abstract: In this paper, we introduce three new subclasses of $\mathrm{m}$-fold symmetric holomorphic functions in the open unit disk $U$, where the functions $f$ and $f^{-1}$ are $\mathrm{m}$-fold symmetric holomorphic functions in the open unit disk. We denote these classes of functions by $F S_{\Sigma, m}^{p, q, s}(d), F S_{\Sigma, m}^{p, q, s}(e)$ and $F S_{\Sigma, m}^{p, q, s, h, r}$. As the Fekete-Szegö problem for different classes of functions is a topic of great interest, we study the Fekete-Szegö functional and we obtain estimates on coefficients for the new function classes.

Keywords: Fekete-Szegö problem; coeffcient bounds and coeffcient estimates; bi-univalent functions; bi-pseudo-starlike functions; $\mathrm{m}$-fold symmetric; analytic functions

\section{Introduction and Preliminary Results}

Let $\mathcal{A}$ denote the family of functions of the form

$$
f(z)=z+\sum_{k=2}^{\infty} a_{k} z^{k}
$$

which are analytic in the open unit disk $U=\{z \in \mathbb{C}:|z|<1\}$ and normalized by the conditions $f(0)=0, f^{\prime}(0)=1$.

Let $S \subset \mathcal{A}$ denote the subclass of all functions in $\mathcal{A}$ which are univalent in $U$ (see [1]).

In [1], the Koebe one-quarter theorem ensures that the image of the unit disk under every $f \in S$ function contains a disk of radius $1 / 4$.

It is well known that every function $f \in S$ has an inverse $f^{-1}$, which is defined by

$$
f^{-1}(f(z))=z, z \in U
$$

and

$$
f\left(f^{-1}(w)\right)=w,|w|<r_{0}(f), r_{0}(f) \geq 1 / 4
$$

where

$$
g(w)=f^{-1}(w)=w-a_{2} w^{2}+\left(2 a_{2}^{2}-a_{3}\right) w^{3}-\left(5 a_{2}^{3}-5 a_{2} a_{3}+a_{4}\right) w^{4}+\ldots
$$

A function $f \in \mathcal{A}$ is said to be bi-univalent in $U$ if both $f$ and $f^{-1}$ are univalent in $U$. Let $\Sigma$ denote the class of all bi-univalent functions in $U$ given by (1).

The class of bi-univalent functions was first introduced and studied by Lewin [2] and it was shown that $\left|a_{2}\right|<1.51$.

The domain $D$ is $m$-fold symmetric if a rotation of $D$ about the origin through an angle $2 \pi / m$ carries $D$ on itself.

We said that the holomorphic function $f$ in the domain $D$ is $m$-fold symmetric if the following condition is true: $f\left(e^{\frac{2 \pi i}{m}} z\right)=e^{\frac{2 \pi i}{m}} f(z)$. 
A function is said to be $\mathrm{m}$-fold symmetric if it has the following normalized form:

$$
f(z)=z+\sum_{k=1}^{\infty} a_{m k+1} z^{m k+1}, z \in U, m \in \mathbb{N} \cup\{0\} .
$$

The normalized form of $f$ is given as in (3) and the series expansion for $f^{-1}(z)$ is given below (see [3]):

$$
\begin{gathered}
g(w)=f^{-1}(w)=w-a_{m+1} w^{m+1} \\
+\left[(m+1) a_{m-1}^{2}-a_{2 m+1}\right] w^{2 m+1} \\
-\left[\frac{1}{2}(m+1)(3 m+2) a_{m+1}^{3}-(3 m+2) a_{m+1} a_{2 m+1}+a_{3 m+1}\right] w^{3 m+1}+\ldots
\end{gathered}
$$

We can give examples of $\mathrm{m}$-fold symmetric bi-univalent functions: $\left\{\frac{z^{m}}{1-z^{m}}\right\}^{\frac{1}{m}}$; $\left[-\log \left(1-z^{m}\right)\right]^{\frac{1}{m}} ; \frac{1}{2} \log \left(\frac{1+z^{m}}{1-z^{m}}\right)^{\frac{1}{m}}$

The important results about the $\mathrm{m}$-fold symmetric analytic bi-univalent functions are given in [3-7].

The Fekete-Szegö problem is the problem of maximizing the absolute value of the functional $\left|a_{3}-\mu a_{2}^{2}\right|$.

Fekete-Szegö inequalities for different classes of functions are studied in the papers [8-14].

Many authors obtained coefficient estimates of bi-univalent functions in the articles [2,14-25].

Definition 1. Let $f \in \mathcal{A}$ be given by (1) and $0<q<p \leq 1$. Then, the $(p, q)$-derivative operator for the function $f$ of the form (1) is defined by

$$
D_{p, q} f(z)=\frac{f(p z)-f(q z)}{(p-q) z}, z \in U^{*}=U-\{0\}
$$

and

$$
\left(D_{p, q} f\right)(0)=f^{\prime}(0)
$$

and it follows that the function $f$ is differentiable at 0 .

We deduce from (2) that

$$
D_{p, q} f(z)=1+\sum_{k=2}^{\infty}[k]_{p, q} a_{k} z^{k-1}
$$

where the $(p, q)$-bracket number is given by

$$
[k]_{p, q}=\frac{p^{k}-q^{k}}{p-q}=p^{k-1}+p^{k-2} q+p^{k-3} q^{2}+\ldots+p q^{k-2}+q^{k-1}, p \neq q
$$

which is a natural generalization of the $q$-number.

Too $\lim _{p \rightarrow 1^{-}}[k]_{p, q}=[k]_{q}=\frac{1-q^{k}}{1-q}$, see $[26,27]$.

Definition 2 ([28]). Let the function $f \in \mathcal{A}$, where $0 \leq d<1, s \geq 1$ is real. The function $f \in L_{s}(d)$ of s-pseudo-starlike function of order $d$ in the unit disk $U$ if and only if

$$
\operatorname{Re}\left(\frac{z\left[f^{\prime}(z)\right]^{s}}{f(z)}\right)>d .
$$


Lemma 1 ([1], p. 41). Let the function $w \in \mathcal{P}$ be given by the following series: $w(z)=$ $1+w_{1} z+w_{2} z^{2}+\ldots, z \in U$, where we denote by $\mathcal{P}$ the class of Carathédory functions analytic in the open disk $U$,

$$
\mathcal{P}=\{w \in \mathcal{A} \mid w(0)=1, \operatorname{Re}(w(z))>0, z \in U\} .
$$

The sharp estimate given by $\left|w_{n}\right| \leq 2, n \in \mathbb{N}^{*}$ holds true.

\section{Main Results}

Definition 3. The function $f$ given by (3) is in the function class $F S_{\Sigma, m}^{p, q, s}(d)(m \in \mathbb{N}$, $0<q<p \leq 1, s \geq 1,0<d \leq 1,(z, w) \in U)$ if:

$$
\left\{\begin{array}{l}
f \in \Sigma, \\
\left|\arg \left(D_{p, q} f(z)\right)^{s}\right|<\frac{d \pi}{2}, z \in U
\end{array}\right.
$$

and

$$
\left|\arg \left(D_{p, q} g(w)\right)^{s}\right|<\frac{d \pi}{2}, w \in U
$$

where $g$ is the function given by (4).

Remark 1. In the case when $m=1$ (one-fold case) and $s=1$, we obtain the class defined in [29].

Remark 2. In the case when $p=1$, we obtain $\lim _{q \rightarrow 1^{-}} F S_{\Sigma, 1}^{1}(d)=F S_{\Sigma}(d)$, the class which was introduced by Srivastava et al. in [24].

We obtain coefficient bounds for the functions class $F S_{\Sigma, m}^{p, q, s}(d)$ in the next theorem.

Theorem 1. Let $f$ given by (3) be in the class $F S_{\Sigma, m}^{p, q, s}(d)(m \in \mathbb{N}, 0<q<p \leq 1, s \geq 1$, $0<d \leq 1,(z, w) \in U)$. Then,

$$
\left|a_{m+1}\right| \leq \frac{2 d}{\sqrt{s d(m+1)[2 m+1]_{p, q}-s(d-s)[m+1]_{p, q}^{2}}}
$$

and

$$
\left|a_{2 m+1}\right| \leq \frac{2 d}{s[2 m+1]_{p, q}}+\frac{2(m+1) d^{2}}{s^{2}[m+1]_{p, q}^{2}} .
$$

Proof. If we use the relations (8) and (9), we obtain

$$
\left(D_{p, q} f(z)\right)^{s}=[\alpha(z)]^{d}
$$

and

$$
\left(D_{p, q} g(w)\right)^{s}=[\beta(w)]^{d},(z, w \in U)
$$

where the functions $\alpha(z)$ and $\beta(w)$ are in $\mathcal{P}$ and are given by

$$
\alpha(z)=1+\alpha_{m} z^{m}+\alpha_{2 m} z^{2 m}+\alpha_{3 m} z^{3 m}+\ldots
$$

and

$$
\beta(w)=1+\beta_{m} w^{m}+\beta_{2 m} w^{2 m}+\beta_{3 m} w^{3 m}+\ldots
$$

It is obvious that

$$
\begin{gathered}
{[\alpha(z)]^{d}=1+d \alpha_{m} z^{m}+\left(d \alpha_{2 m}+\frac{d(d-1)}{2} \alpha_{m}^{2}\right) z^{2 m}+\ldots,} \\
{[\beta(w)]^{d}=1+d \beta_{m} w^{m}+\left(d \beta_{2 m}+\frac{d(d-1)}{2} \beta_{m}^{2}\right) w^{2 m}+\ldots,}
\end{gathered}
$$




$$
\begin{gathered}
\left(D_{p, q} f(z)\right)^{s}=1+s[m+1]_{p, q} a_{m+1} z^{m} \\
+\left(s[2 m+1]_{p, q} a_{2 m+1}+\frac{s(s-1)}{2}[m+1]_{p, q}^{2} a_{m+1}^{2}\right) z^{2 m}+\ldots
\end{gathered}
$$

and

$$
\begin{gathered}
\left(D_{p, q} g(w)\right)^{s}=1-s[m+1]_{p, q} a_{m+1} w^{m} \\
-s[2 m+1]_{p, q} a_{2 m+1} w^{2 m}+\left(s(m+1)[2 m+1]_{p, q} a_{m+1}^{2}+\frac{s(s-1)}{2}[m+1]_{p, q}^{2} a_{m+1}^{2}\right) w^{2 m}+\ldots
\end{gathered}
$$

If we compare the coefficients in the relations (12) and (13), we have

$$
\begin{gathered}
s[m+1]_{p, q} a_{m+1}=d \alpha_{m}, \\
s[2 m+1]_{p, q} a_{2 m+1}+\frac{s(s-1)}{2}[m+1]_{p, q}^{2} a_{m+1}^{2} \\
=d \alpha_{2 m}+\frac{d(d-1)}{2} \alpha_{m}^{2} \\
-s[m+1]_{p, q} a_{m+1}=d \beta_{m,} \\
-s[2 m+1]_{p, q} a_{2 m+1}+\left(s(m+1)[2 m+1]_{p, q}+\frac{s(s-1)}{2}[m+1]_{p, q}^{2}\right) a_{m+1}^{2} \\
=d \beta_{2 m}+\frac{d(d-1)}{2} \beta_{m}^{2} .
\end{gathered}
$$

We obtain from the relations (16) and (18)

$$
\alpha_{m}=-\beta_{m}
$$

and

$$
2 s^{2}[m+1]_{p, q}^{2} a_{m+1}^{2}=d^{2}\left(\alpha_{m}^{2}+\beta_{m}^{2}\right)
$$

Now, from the relations (17), (19) and (21), we obtain that

$$
\begin{gathered}
s(s-1) d[m+1]_{p, q}^{2} a_{m+1}^{2}+(m+1) s d[2 m+1]_{p, q} a_{m+1}^{2} \\
-(d-1) s^{2}[m+1]_{p, q}^{2} a_{m+1}^{2}=d^{2}\left(\alpha_{2 m}+\beta_{2 m}\right) .
\end{gathered}
$$

We have

$$
a_{m+1}^{2}=\frac{d^{2}\left(\alpha_{2 m}+\beta_{2 m}\right)}{s[m+1]_{p, q}^{2}(s-d)+(m+1) s d[2 m+1]_{p, q}} .
$$

If we apply Lemma 1 for the coefficients $\alpha_{2 m}$ and $\beta_{2 m}$, we have

$$
\left|a_{m+1}\right| \leq \frac{2 d}{\sqrt{(m+1) s d[2 m+1]_{p, q}-(d-s) s[m+1]_{p, q}^{2}}}
$$

If we use the relations (17) and (19), we obtain the next relation

$$
\begin{gathered}
2 s[2 m+1]_{p, q} a_{2 m+1}-s(m+1)[2 m+1]_{p, q} a_{m+1}^{2} \\
=d\left(\alpha_{2 m}-\beta_{2 m}\right)+\frac{d(d-1)}{2}\left(\alpha_{m}^{2}-\beta_{m}^{2}\right) .
\end{gathered}
$$

It follows from (20), (21) and (23) that

$$
a_{2 m+1}=\frac{(m+1) d^{2}\left(\alpha_{m}^{2}+\beta_{m}^{2}\right)}{4 s^{2}[m+1]_{p, q}^{2}}+\frac{d\left(\alpha_{2 m}-\beta_{2 m}\right)}{2 s[2 m+1]_{p, q}} .
$$


If we apply Lemma 1 for the coefficients $\alpha_{m}, \alpha_{2 m}, \beta_{m}, \beta_{2 m}$, we obtain

$$
\left|a_{2 m+1}\right| \leq \frac{2 d}{[2 m+1]_{p, q} s}+\frac{2 d^{2}(m+1)}{s^{2}[m+1]_{p, q}^{2}}
$$

Remark 3. For one-fold case $m=1$ and $s=1$ in Theorem 1, we obtain the results obtained in [29].

Remark 4. For a one-fold case and $p=1$, we have

$$
\lim _{q \rightarrow 1^{-}} F S_{\Sigma, 1}^{q, 1}(d)=F S_{\Sigma}(d)
$$

the results of Srivastava et al. [24].

Definition 4. The function $f$ given by (3) is in the class $F S_{\Sigma, m}^{p, q, s}(e)(0 \leq e<1,0<q<p \leq 1, s \geq 1$, $(z, w) \in U, m \in \mathbb{N})$ if the following conditions are satisfied:

$$
\begin{aligned}
& \left\{\begin{array}{l}
f \in \Sigma, \\
\mathcal{R}\left\{\left(D_{p, q} f(z)\right)^{s}\right\}>e, z \in U
\end{array}\right. \\
& \mathcal{R}\left\{\left(D_{p, q} g(w)\right)^{s}\right\}>e, w \in U,
\end{aligned}
$$

where the function $g$ is defined by Relation (4).

Remark 5. For $m=1$ (one-fold case) and $s=1$, we obtain the class of functions obtained in [29].

Remark 6. When $p=1$, we obtain $\lim _{q \rightarrow 1^{-}} F S_{\Sigma, 1}^{1}(e)=F S_{\Sigma}(d)$, the class which was introduced by Srivastava et al. in [24].

In the next theorem, we obtain coefficient bounds for the function class $F S_{\Sigma, m}^{p, q, s}(e)$.

Theorem 2. Let the function $f$ given by (3) be in the function class $F S_{\Sigma, m}^{p, q, s}(e),(m \in \mathbb{N}$, $0<q<p \leq 1, s \geq 1,0 \leq e<1,(z, w) \in U)$. Then,

$$
\begin{gathered}
\left|a_{m+1}\right| \leq \min \left\{\frac{2(1-e)}{s[m+1]_{p, q}}, 2 \sqrt{\frac{(1-e)}{s(s-1)[m+1]_{p, q}^{2}+(m+1) s[2 m+1]_{p, q}}}\right\} \\
\left|a_{2 m+1}\right| \leq \frac{2(1-e)(m+1)}{s(s-1)[m+1]_{p, q}^{2}+(m+1) s[2 m+1]_{p, q}}+\frac{2(1-e)}{s[2 m+1]_{p, q}}
\end{gathered}
$$

Proof. If we use Relations (25) and (26), we obtain

$$
\left(D_{p, q} f(z)\right)^{S}=e+(1-e) \alpha(z)
$$

and

$$
\left(D_{p, q} g(w)\right)^{s}=e+(1-e) \beta(w), \quad z, w \in U
$$

respectively, where

$$
\alpha(z)=1+\alpha_{m} z^{m}+\alpha_{2 m} z^{2 m}+\alpha_{3 m} z^{3 m}+\ldots
$$

and

$$
\beta(w)=1+\beta_{m} w^{m}+\beta_{2 m} w^{2 m}+\beta_{3 m} w^{3 m}+\ldots
$$

$\alpha(z)$ and $\beta(w)$ are in $\mathcal{P}$. 
It is obvious that

$$
e+(1-e) \alpha(z)=1+(1-e) \alpha_{m} z^{m}+(1-e) \alpha_{2 m} z^{2 m}+\ldots,
$$

and

$$
e+(1-e) \beta(w)=1+(1-e) \beta_{m} w^{m}+(1-e) \beta_{2 m} w^{2 m}+\ldots
$$

Already,

$$
\left(D_{p, q} f(z)\right)^{s}=1+s[m+1]_{p, q} a_{m+1} z^{m}+\left(s[2 m+1]_{p, q} a_{2 m+1}+\frac{s(s-1)}{2}[m+1]_{p, q}^{2} a_{m+1}^{2}\right) z^{2 m}+\ldots
$$

and

$$
\begin{aligned}
& \left(D_{p, q} g(w)\right)^{s}=1-s[m+1]_{p, q} a_{m+1} w^{m}-s[2 m+1]_{p, q} a_{2 m+1} w^{2 m} \\
& +\left(s(m+1)[2 m+1]_{p, q} a_{m+1}^{2}+\frac{s(s-1)}{2}[m+1]_{p, q}^{2} a_{m+1}^{2}\right) w^{2 m}+\ldots
\end{aligned}
$$

From the relations (29) and (30), if we compare the coefficients, we obtain the following relations:

$$
\begin{gathered}
s[m+1]_{p, q} a_{m+1}=(1-e) \alpha_{m}, \\
s[2 m+1]_{p, q} a_{2 m+1}+\frac{s(s-1)}{2}[m+1]_{p, q}^{2} a_{m+1}^{2}=(1-e) \alpha_{2 m}, \\
-s[m+1]_{p, q} a_{m+1}=(1-e) \beta_{m}, \\
-s[1+2 m]_{p, q} a_{2 m+1}+\left(s[2 m+1]_{p, q}(m+1)\right. \\
\left.+\frac{s(s-1)}{2}[1+m]_{p, q}^{2}\right) a_{m+1}^{2}=(1-e) \beta_{2 m} .
\end{gathered}
$$

We obtain from Relations (31) and (33)

$$
\alpha_{m}=-\beta_{m}
$$

and

$$
2 s^{2}[m+1]_{p, q}^{2} a_{m+1}^{2}=(1-e)^{2}\left(\alpha_{m}^{2}+\beta_{m}^{2}\right) .
$$

We obtain now from Relations (32) and (34) the following relation:

$$
\begin{gathered}
s(s-1)[m+1]_{p, q}^{2} a_{m+1}^{2}+(m+1) s[2 m+1]_{p, q} a_{m+1}^{2}= \\
(1-e)\left(\alpha_{2 m}+\beta_{2 m}\right) .
\end{gathered}
$$

From Lemma 1 for the coefficients $\alpha_{m}, \alpha_{2 m}, \beta_{m}, \beta_{2 m}$, we obtain that

$$
\left|a_{m+1}\right| \leq 2 \sqrt{\frac{1-e}{(m+1) s[2 m+1]_{p, q}+s(s-1)[m+1]_{p, q}^{2}}} .
$$

If we use Relations (32) and (34) to find the bound on $\left|a_{2 m+1}\right|$, we obtain the following relation:

$$
-s(1+m)[1+2 m]_{p, q} a_{m+1}^{2}+2 s[1+2 m]_{p, q} a_{2 m+1}=(1-e)\left(\alpha_{2 m}-\beta_{2 m}\right),
$$

or equivalently

$$
a_{2 m+1}=\frac{(1-e)\left(\alpha_{2 m}-\beta_{2 m}\right)}{2 s[2 m+1]_{p, q}}+\frac{(m+1)}{2} a_{m+1}^{2} .
$$

From Relation (36), if we substitute the value of $a_{m+1}^{2}$, we obtain

$$
a_{2 m+1}=\frac{(1-e)\left(\alpha_{2 m}-\beta_{2 m}\right)}{2 s[2 m+1]_{p, q}}+\frac{(m+1)(1-e)^{2}\left(\alpha_{m}^{2}+\beta_{m}^{2}\right)}{4 s^{2}[m+1]_{p, q}^{2}} .
$$


Now, if we apply Lemma 1 for the coefficients $\alpha_{m}, \alpha_{2 m}, \beta_{m}, \beta_{2 m}$, we obtain

$$
\left|a_{2 m+1}\right| \leq \frac{2(1-e)}{s[2 m+1]_{p, q}}+\frac{2(m+1)(1-e)^{2}}{s^{2}[m+1]_{p, q}^{2}} .
$$

From Relations (37) and (39) applying Lemma 1, we obtain

$$
\left|a_{2 m+1}\right| \leq \frac{2(m+1)(1-e)}{s(s-1)[m+1]_{p, q}^{2}+(m+1) s[2 m+1]_{p, q}}+\frac{2(1-e)}{s[2 m+1]_{p, q}} .
$$

Remark 7. For one fold case $(m=1)$ and $s=1$ in Theorem 2, we obtain the results given in [29].

Remark 8. For a one-fold case, in Theorem 2, choosing $p=1, q \rightarrow 1^{-}$, we obtain the following corollary.

Corollary 1. [24] Let the function $f \in F S_{\Sigma}(e),(s=1,0 \leq e<1,(z, w) \in U)$ be given by (1). Then,

$$
\left|a_{2}\right| \leq \sqrt{\frac{2(1-e)}{3}}
$$

and

$$
\left|a_{3}\right| \leq \frac{(1-e)(5-3 e)}{3} .
$$

In the following theorems, we provide the Fekete-Szegö type inequalities for the functions of the families $F S_{\Sigma, m}^{p, q, s}(d)$ and $F S_{\Sigma, m}^{p, q, s}(e)$.

Theorem 3. Let $f$ be a function of the form (3) in the class $F S_{\Sigma, m}^{p, q, s}(d)$. Then,

$$
\left|a_{2 m+1}-\sigma a_{m+1}^{2}\right| \leq\left\{\begin{array}{l}
\frac{2 d}{s[2 m+1]_{p, q}},|t(\sigma)| \leq \frac{1}{s[2 m+1]_{p, q}} \\
4 s d|t(\sigma)|,|t(\sigma)| \geq \frac{1}{s[2 m+1]_{p, q}},
\end{array}\right.
$$

where

$$
t(\sigma)=\frac{d(m+1-2 \sigma)}{2 s[m+1]_{p, q}^{2}(s-d)+2 s(m+1) d[2 m+1]_{p, q}} .
$$

Proof. We want to calculate $a_{2 m+1}-\sigma a_{m+1}^{2}$.

For this, from Relations (22) and (24), where we know the values of the coefficients $a_{m+1}^{2}$ and $a_{2 m+1}$ :

$$
\begin{gathered}
a_{m+1}^{2}=\frac{d^{2}\left(\alpha_{2 m}+\beta_{2 m}\right)}{s[m+1]_{p, q}^{2}(s-d)+(m+1) s d[2 m+1]_{p, q}}, \\
a_{2 m+1}=\frac{(m+1) d^{2}\left(\alpha_{m}^{2}+\beta_{m}^{2}\right)}{4 s^{2}[m+1]_{p, q}^{2}}+\frac{d\left(\alpha_{2 m}-\beta_{2 m}\right)}{2 s[2 m+1]_{p, q}},
\end{gathered}
$$

it follows that

$$
\begin{gathered}
a_{2 m+1}-\sigma a_{m+1}^{2}= \\
d\left[\alpha_{2 m}\left(\frac{1}{2 s[2 m+1]_{p, q}}+\frac{d(m+1-2 \sigma)}{2 s[m+1]_{p, q}^{2}(s-d)+2 s(m+1) d[2 m+1]_{p, q}}\right)\right. \\
\left.+\beta_{2 m}\left(\frac{d(m+1-2 \sigma)}{2 s[m+1]_{p, q}^{2}(s-d)+2 s d(m+1)[2 m+1]_{p, q}}-\frac{1}{2 s[2 m+1]_{p, q}}\right)\right] .
\end{gathered}
$$


According to Lemma 1 and after some computations, we obtain

$$
\left|a_{2 m+1}-\sigma a_{m+1}^{2}\right| \leq\left\{\begin{array}{l}
\frac{2 d}{s[2 m+1]_{p, q}},|t(\sigma)| \leq \frac{1}{s[2 m+1]_{p, q}} \\
4 s d|t(\sigma)|,|t(\sigma)| \geq \frac{1}{s[2 m+1]_{p, q}} .
\end{array}\right.
$$

Theorem 4. Let $f$ be a function of the form (3) in the class $F S_{\Sigma, m}^{p, q, s}(e)$. Then,

$$
\left|a_{2 m+1}-\sigma a_{m+1}^{2}\right| \leq\left\{\begin{array}{l}
\frac{2(1-e)}{s[2 m+1]_{p, q}},|t(\sigma)| \leq \frac{1}{2 s[2 m+1]_{p, q}} \\
4 s(1-e)|t(\sigma)|,|t(\sigma)| \geq \frac{1}{2 s[2 m+1]_{p, q}}
\end{array},\right.
$$

where

$$
t(\sigma)=\frac{(1-2 \sigma+m)}{2 s(s-1) d[m+1]_{p, q}^{2}+2 s(m+1)[2 m+1]_{p, q}} .
$$

Proof. We will compute $a_{2 m+1}-\sigma a_{m+1}^{2}$, using the values of the coefficients $a_{m+1}^{2}$ and $a_{2 m+1}$ given in Relations (37) and (39).

It follows that

$$
\begin{gathered}
a_{2 m+1}-\sigma a_{m+1}^{2} \\
=(1-e)\left[\alpha_{2 m}\left(\frac{1}{2 s[2 m+1]_{p, q}}+\frac{1-2 \sigma+m}{2 s(s-1) d[m+1]_{p, q}^{2}+2(m+1) s[2 m+1]_{p, q}}\right)\right. \\
\left.+\beta_{2 m}\left(\frac{(1+m-2 \sigma)}{2 s(s-1) d[m+1]_{p, q}^{2}+2 s(m+1)[2 m+1]_{p, q}}-\frac{1}{2 s[2 m+1]_{p, q}}\right)\right] .
\end{gathered}
$$

According to Lemma 1 and after some computations, we obtain

$$
\left|a_{2 m+1}-\sigma a_{m+1}^{2}\right| \leq\left\{\begin{array}{l}
\frac{2(1-e)}{s[2 m+1]_{p, q}},|t(\sigma)| \leq \frac{1}{2 s[2 m+1]_{p, q}} \\
4 s(1-e)|t(\sigma)|,|t(\sigma)| \geq \frac{1}{2 s[2 m+1]_{p, q}}
\end{array} .\right.
$$

Definition 5. Let $h, r: U \rightarrow \mathbb{C}$ be analytic functions and $\min \{\operatorname{Re}(h(z)), \operatorname{Re}(r(z))\}>0$, where $z \in U, h(0)=r(0)=1$.

A function $f$ given by (3) is said to be in the class $F S_{\Sigma, m}^{p, q, s, h, r}$, where $s \geq 1,0<q<p \leq 1$, $m \in \mathbb{N}$ if the conditions are satisfied:

$$
\left(D_{p, q} f(z)\right)^{s} \in h(U), z \in U
$$

and

$$
\left(D_{p, q} g(w)\right)^{s} \in r(U), w \in U,
$$

where the function $g$ is given by (4).

We obtain coefficient bounds for the functions class $F S_{\Sigma, m}^{p, q, s, h, r}$ in the following theorem.

Theorem 5. Let the function $f$ given by (3) be in the class $F S_{\Sigma, m}^{p, q, s, h, r}$. Then,

$$
\left|a_{m+1}\right| \leq \min \left\{\sqrt{\frac{\left|h_{1}^{\prime}(0)\right|^{2}+\left|r_{1}^{\prime}(0)\right|^{2}}{2 s^{2}[m+1]_{p, q}^{2}}}, \sqrt{\frac{\left|h_{2}^{\prime \prime}(0)\right|+\left|r_{2}^{\prime \prime}(0)\right|}{s(s-1)[m+1]_{p, q}^{2}+s(m+1)[2 m+1]_{p, q}}}\right\} ;
$$




$$
\begin{aligned}
& \left|a_{2 m+1}\right| \leq \min \left\{\frac{\left(\left|h^{\prime}(0)\right|^{2}+\left|r^{\prime}(0)\right|^{2}\right)(m+1)}{4 s^{2}[m+1]_{p, q}^{2}}+\frac{\left|h^{\prime \prime}(0)\right|+\left|t^{\prime \prime}(0)\right|}{2 s[2 m+1]_{p, q}},\right. \\
& \left.\frac{\left|h^{\prime \prime}(0)\right|+\left|r^{\prime \prime}(0)\right|}{2 s[2 m+1]_{p, q}}+\frac{(m+1)\left(\left|h^{\prime \prime}(0)\right|+\left|r^{\prime \prime}(0)\right|\right)}{2 s\left\{(m+1)[2 m+1]_{p, q}+(s-1)[m+1]_{p, q}^{2}\right\}}\right\} .
\end{aligned}
$$

Proof. In Relations (43) and (44), the equivalent forms of the argument inequalities are

$$
\left(D_{p, q} f(z)\right)^{s}=h(z),
$$

and

$$
\left(D_{p, q} g(w)\right)^{s}=r(w),
$$

where $h(z)$ and $r(w)$ satisfy the conditions from Definition 5, and have the following Taylor-Maclaurin series expansions:

$$
\begin{aligned}
& h(z)=1+h_{1} z+h_{2} z^{2}+\ldots \\
& r(w)=1+r_{1} w+r_{2} w^{2}+\ldots
\end{aligned}
$$

If we substitute (49) and (50) into (47) and (48), respectively, and equate the coefficients, we obtain

$$
\begin{gathered}
s[m+1]_{p, q} a_{m+1}=h_{1} ; \\
s[2 m+1]_{p, q} a_{2 m+1}+\frac{s(s-1)}{2}[m+1]_{p, q}^{2} a_{m+1}^{2}=h_{2} ; \\
-s[m+1]_{p, q} a_{m+1}=r_{1} ; \\
-s[2 m+1]_{p, q} a_{2 m+1}+\left(s(m+1)[2 m+1]_{p, q}+\frac{s(s-1)}{2}[m+1]_{p, q}^{2}\right) a_{m+1}^{2}=r_{2} .
\end{gathered}
$$

We obtain that

$$
h_{1}=-r_{1}
$$

and

$$
h_{1}^{2}+r_{1}^{2}=2 s^{2}[m+1]_{p, q}^{2} a_{m+1}^{2}
$$

from Relations (51) and (53).

Adding Relations (52) and (54), we obtain that

$$
a_{m+1}^{2}\left\{s(s-1)[m+1]_{p, q}^{2}+s(m+1)[2 m+1]_{p, q}\right\}=h_{2}+r_{2} .
$$

Now, from (56) and (57), we obtain

$$
\begin{gathered}
a_{m+1}^{2}=\frac{h_{1}^{2}+r_{1}^{2}}{2 s^{2}[m+1]_{p, q}^{2}} \\
a_{m+1}^{2}=\frac{h_{2}+r_{2}}{s(s-1)[m+1]_{p, q}^{2}+s(m+1)[2 m+1]_{p, q}} .
\end{gathered}
$$

We obtain from Relations (58) and (59) that

$$
\left|a_{m+1}\right|^{2} \leq \frac{\left|h_{1}^{\prime}(0)\right|^{2}+\left|r_{1}^{\prime}(0)\right|^{2}}{2 s^{2}[m+1]_{p, q}^{2}}
$$

and

$$
\left|a_{m+1}\right|^{2} \leq \frac{\left|h_{2}^{\prime \prime}(0)\right|+\left|r_{2}^{\prime \prime}(0)\right|}{s(s-1)[m+1]_{p, q}^{2}+s(m+1)[2 m+1]_{p, q}} .
$$

So, we obtain the estimate on the coefficient $\left|a_{m+1}\right|$ as in (45). 
Next, substracting (54) from (52), we obtain the following relation:

$$
2 s[2 m+1]_{p, q} a_{2 m+1}-s(m+1)[2 m+1]_{p, q} a_{m+1}^{2}=h_{2}-r_{2} .
$$

Substituting the value of $a_{m+1}^{2}$ from (58) into (60), it follows that

$$
a_{2 m+1}=\frac{h_{2}-r_{2}}{2 s[2 m+1]_{p, q}}+\frac{(m+1)\left(h_{1}^{2}+r_{1}^{2}\right)}{4 s^{2}[m+1]_{p, q}^{2}} \text {. }
$$

Therefore,

$$
\left|a_{2 m+1}\right| \leq \frac{\left(\left|h^{\prime}(0)\right|^{2}+\left|r^{\prime}(0)\right|^{2}\right)(m+1)}{4 s^{2}[m+1]_{p, q}^{2}}+\frac{\left|h^{\prime \prime}(0)\right|+\left|t^{\prime \prime}(0)\right|}{2 s[2 m+1]_{p, q}} .
$$

Upon substituting the value of $a_{m+1}^{2}$ from (59) into (60), it follows that

$$
a_{2 m+1}=\frac{h_{2}-r_{2}}{2 s[2 m+1]_{p, q}}+\frac{(m+1)\left(h_{2}+r_{2}\right)}{\left\{(s-1)[m+1]_{p, q}^{2}+(m+1)[2 m+1]_{p, q}\right\} 2 s} .
$$

So, it follows that

$$
\left|a_{2 m+1}\right| \leq \frac{\left|h^{\prime \prime}(0)\right|+\left|r^{\prime \prime}(0)\right|}{2 s[2 m+1]_{p, q}}+\frac{(m+1)\left(\left|h^{\prime \prime}(0)\right|+\left|r^{\prime \prime}(0)\right|\right)}{2 s\left\{(m+1)[2 m+1]_{p, q}+(s-1)[m+1]_{p, q}^{2}\right\}}
$$

\section{Conclusions}

As future research directions, the symmetry properties of this operator, the $(p, q)$ derivative operator, can be studied.

Author Contributions: Conceptualization, D.B. and L.-I.C.; Data curation, L.-I.C.; Investigation, L.-I.C.; Methodology, D.B. and L.-I.C.; Project administration, D.B. and L.-I.C.; Resources, D.B. and L.-I.C.; Validation, D.B. and L.-I.C.; Visualization, D.B.; Writing-review and editing, D.B. and L.-I.C. All authors have read and agreed to the published version of the manuscript.

Funding: This research received no external funding.

Institutional Review Board Statement: Not applicable.

Informed Consent Statement: Not applicable.

Data Availability Statement: Not applicable.

Acknowledgments: The authors would like to thank the referees for their careful reading and helpful comments.

Conflicts of Interest: The authors declare no conflict of interest.

\section{References}

1. Duren, P.L. Univalent Functions, Grundlehren der Mathematischen Wissenschaften; Springer: New York, NY, USA, 1983; ISBN 0-387-90795-5.

2. Lewin, M. On a coefficient problem for bi-univalent functions. Proc. Am. Math. Soc. 1967, 18, 63-68. [CrossRef]

3. Srivastava, H.M.; Sivasubramanian, S.; Sivakumar, R. Initial coefficient bounds for a subclass of m-fold symmetric bi-univalent functions. Tbil. Math. J. 2014, 7, 1-10. [CrossRef]

4. Altinkaya, Ş.; Yalçin, S. On some subclasses of m-fold symmetric bi-univalent functions. Commun. Fac. Sci. Univ. Ank. Ser. Math Stat. 2018, 67, 29-36.

5. Eker, S.S. Coefficient bounds for subclasses of m-fold symmetric bi-univalent functions. Turk. J. Math. 2016, 40, 641-646. [CrossRef]

6. Hamidi, S.G.; Jahangiri, J.M. Unpredictability of the coefficients of m-fold symmetric bi-starlike functions. Int. J. Math. 2014, 25, 1450064. [CrossRef] 
7. Sakar, F.M.; Guney, M.O. Coefficient estimates for certain subclasses of $\mathrm{m}$-fold symmetric bi-univalent functions defined by the q-derivative operator, Konuralp. J. Math. 2018, 6, 279-285.

8. Bucur, R.; Andrei, L.; Breaz, D. Coefficient bounds and Fekete-Szegö problem for a class of analytic functions defined by using a new differential operator. Appl. Math. Sci. 2015, 9, 1355-1368.

9. Catas, A. On the Fekete-Szegö problem for certain classes of meromorphic functions using p,q-derivative operator and a p,q-wright type hypergeometric function. Symmetry 2021, 13, 2143. [CrossRef]

10. Dziok, J. A general solution of the Fekete-Szegö problem. Bound Value Probl. 2013, 98, 13. [CrossRef]

11. Fekete, M.; Szegö, G. Eine bemerkung über ungerade schlichte funktionen. J. Lond. Math. Soc. 1933, 8, 85-89. [CrossRef]

12. Kanas, S. An unified approach to the Fekete-Szegö problem. Appl. Math. Comput. 2012, 218, 8453-8461. [CrossRef]

13. Páll-Szabó, A.O.; Oros, G.I. Coefficient Related Studies for New Classes of Bi-Univalent Functions. Mathematics 2020, 8, 1110. [CrossRef]

14. Wanas, A.K.; Cotirla, L.I. Initial coefficient estimates and Fekete-Szegö inequalities for new families of bi-univalent functions governed by $(p-q)$-Wanas operator. Symmetry 2021, 13, 2118. [CrossRef]

15. Altinkaya, Ş.; Yalçin, S. Faber polynomial coefficient bounds for a subclass of bi-univalent functions. C. R. Math. Acad. Sci. Paris 2015, 353, 1075-1080. [CrossRef]

16. Breaz, V.D.; Catas, A.; Cotîrlă, L. On the Upper Bound of the Third Hankel Determinant for Certain Class of Analytic Functions Related with Exponential Function; Analele Universitatii Ovidius Constanta: Constanta, Romania, 2022.

17. El-Deeb, S.M.; Bulboacă, T.; El-Matary, B.M. Maclaurin Coefficient Estimates of Bi-Univalent Functions Connected with the q-Derivative. Mathematics 2020, 8, 418. [CrossRef]

18. Govindaraj, M.; Sivasubramanian, S. On a class of analytic functions related to conic domains involving q-calculus. Anal. Math 2017, 43, 475-487. [CrossRef]

19. Jahangiri, J.M.; Hamidi, S.G. Faber polynomial coefficient estimates for analytic bi-Bazilevic functions. Mat. Vesnik 2015, 67, 123-129.

20. Ma, W.; Minda, D. A unified treatment of some special classes of univalent functions. In Proceedings of the Conference on Complex Analysis, Tianjin, China, 22-27 May 1992; pp. 157-169.

21. Pommerenke, C. Univalent Functions; Vanderhoeck and Ruprecht: Gottingen, Germany, 1975; p. 376.

22. Sivasubramanian, S.; Sivakumar, R.; Kanas, S.; Kim, S.-A. Verification of Brannan and Clunie's conjecture for certain sub-classes of bi-univalent functions. Ann. Polon. Math. 2015, 113, 295-304. [CrossRef]

23. Srivastava, H.M.; Altinkaya, Ş.; Yalçin, S. Hankel Determinant for a Subclass of Bi-Univalent Functions Defined by Using a Symmetric q-Derivative Operator. Filomat 2018, 32, 503-516. [CrossRef]

24. Srivastava, H.M.; Mishra, A.K.; Gochhayat, P. Certain subclasses of analytic and bi-univalent functions. Appl. Math. Lett. 2010, 23, 1188-1192. [CrossRef]

25. Wanas, A.K.; Alb Lupas, A. Applications of Horadam Polynomials on Bazilevic Bi- Univalent Function Satisfying Subordinate Conditions. J. Phys. Conf. Ser. 2019, 1294, 032003. [CrossRef]

26. Corcino, R.B. On $p, q$-binomial coefficients. Integers 2008, 8, 16

27. Sadjang, P.N. On the fundamental theorem of (p,q)-calculus and some (p,q)-Taylor formulas. arXiv 2013, arXiv:1309.3934.

28. Babalola, K.O. On $\lambda$-pseudo-starlike function. J. Class. Anal. 2013, 3, 137-147. [CrossRef]

29. Cotirla, L.I. New classes of analytic and bi-univalent functions. AIMS Math. 2021, 6, 10642-10651. [CrossRef] 